\begin{tabular}{l|cc} 
DE \\
\hline $\mathbf{G}$ & $\begin{array}{l}\text { DE GRUYTER } \\
\text { OPEN }\end{array}$ & ECONOMIC THEMES (2015) $53(3): 432-448$ \\
\hline
\end{tabular}

\title{
TRAINING SYSTEM FOR CRISIS MANAGEMENT SUPPORTED BY CONTEMPORARY INFORMATION TECHNOLOGIES
}

\author{
Vladimir Milićević \\ Higher buciness school of professional studies, Kragujevac, Serbia \\ \vladam.kg@outlook.com
}

Slavoljub Milovanović

University of Niš, Faculty of Economics, Serbia

\smilovan@eknfak.ni.ac.rs

UDC

005.334:004

Review paper

Received:

31.8.2014

Accepted:

24.9.2015

\begin{abstract}
In a transition period lasting more than twenty years in Serbia, many organizations exist in turbulent and uncertain political, economic and social environment. Great changes in the environment with implications which are difficult to predict pose to the management of the organizations many crisis situations. Every manager possessing standard skills and knowledge for enterprise management must acquire additional skills for management of the crisis situations. Crisis management is set of actions undertaken to control over events composing crisis, in order to minimize losses. In order to undertake appropriate actions in crisis time, manager should know the direction of future events movement and how to allocate resources for reaction to the events. In that situation, the great problem is uncertainty resulting from fast and immediate emergence of crisis events, its complexity and unpredictability. Training system that has aim to enable managers for reaction in crisis situations is analysed in the paper. The system is based on application of contemporary information technologies. In addition, trends and opportunities of electronic learning and training as well as challenges in the development of a training program for crisis management is explained.
\end{abstract}

Key words: Crisis management, electronic learning, training system, information technologies

\section{Introduction}

Electronic learning (e-learning) could be defined as the delivery of education content via all electronic media, including the Internet, intranets, extranets, 
satellite broadcast, interactive TV, and CD or DVD. The term e-learning refers to set of applications and processes and includes many other similar terms such as, web-based learning, on-line learning, virtual classrooms, distance learning (Milovanovic, 2010, 191-199).

On-line learning is used synonymously with web-based learning, although terms like e-learning (Tatnall et al. 2005) (Santhanam et al. 2008, 26-47), distance learning (Koohang, Paliszkiewicz, 2013, 109-114) (Wei-Han Tan et al. 2012, 82-91), on-line learning (Azevedo, Scalabrin, 2005, 5-24) (Al-Busaidi, 2012, 11-34) and web-based learning (Kuang-Yuan, 2012, 128-152) (Gupta, Bostrom, 2009, 686-714) are defined and used differently by different organizations and user groups. On-line learning makes just one aspect of elearning and means learning via Internet, intranet, and extranet. Finally, some authors (Urdan, Weggen, 2000) (Driscoll, Carliner, 2005) use the term etraining as a synonym for corporate e-learning. Really, e-training describes corporate training conducted via e-learning methods and technologies.

There are two forms of on-line learning: basic on-line learning and sophisticated on-line learning. A basic on-line learning program includes textual and graphic content of the course, exercises and testing. A sophisticated on-line learning program includes audio and video records, discussion groups, on-line mentoring, animations, simulations, link to course material on the website (Morrison et al. 2012, 80-89).

E-learning can be conducted by synchronous and asynchronous methods and technologies. Synchronous learning takes place in on-line real-time virtual learning environment and lectures are led by an instructor. In the environment all participants are present at the same time and communicate directly with each other. There are many examples of environments for synchronous course delivery: virtual classrooms, teleconferences and videoconferences, Internet telephony, and live satellite broadcasts of lectures to students in a classroom (Franceschi et al. 2009, 73-100).

In the asynchronous learning environment, participants are not present at the same time and thus they communicate with time delay. Examples for asynchronous course delivery are: distribution of courses via Internet or DVD, recorded classes, recorded audio/video web presentations, question\&answer mentoring, on-line chats and discussion groups, and e-mail (Garcia, Pariente, 2009, 252-261).

In this paper a sophisticated e-learning system dedicated to training in domain of crisis management is presented. This system makes synchronous learning environment that supports managers in increasing their ability to make good decisions in time of a crisis. Making good decisions in time of a crisis is very important and at the same time very difficult because mistakes of people that fail to prevent crisis situations are possible. Whereas crises require fast and 
effective decision making, there are many problems in training managers in the skills needed for crisis management. The aim of the paper is to explain the causes of these problems and to offer a solution for them in the form of ITbased training system for crisis management (ITBTS). Sniezek and his colleagues (Sniezek et al. 2002, 147-168) considered psychological problems occurring in training for crisis decision making and proposed computer-based solution. The solution is starting point for blueprint of ITBTS presented in the paper. This blueprint can be used by application developers as a model for development of real e-training systems which could be used in the crisis management domain and the other domains as well.

In order to address described aim of the paper referring to analysis of issues in training for crisis management this research is divided in four parts. In the second part of the paper, contemporary trends and opportunities of e-learning and training are explained. In the third part of the paper, main problems and challenges in training in crisis management are analysed and advanced method of training for crisis management supported by contemporary information technologies is presented. In the final part of the paper, concluding remarks considering technology-based solutions for crisis management training are presented.

\section{Trends and Opportunities of E-Learning}

Today, there are three major trends in e-learning area: integration of many information technologies in education, trainee-friendly environments and service-oriented institutions.

Integration. Many information and communication technologies in education are going to be integrated. The distinctions between different forms of educational telecommunications have reduced. New wireless services in elearning make challenge for further integration of technologies. Therefore, learners and trainees have to be familiar with multiple technologies, to be skillful in information gathering from remote sources and to be trained in collaboration with remote team members (Shi, Whinston, 2013, 185-212).

Trainee-friendly environments. Advances in educational technologies (e.g. natural language processing, simulation and expert systems, reusable learning objects, and agent technology) make learning environments more friendly. Learners and trainees simply describe the desired learning goal and send intelligent agents to collect suitable learning objects from the web. Trainees take responsibility for their own learning, defining their own learning goals and using educational resources and technologies (Sims et al. 2008, 429-442).

Service-Oriented Institutions. The quality of services of e-learning institutions is a key factor influencing the competitive advantage of the 
institutions. The services include: pedagogical services, learning services, and infrastructure. Most of today's learning environments are focused mainly on infrastructure and neglect the personalized pedagogical and learning services (Jingyuan, Ordonez de Pablos, 2009, 241-251).

Content, technology, and services are the three major market segments in elearning, particularly in corporate e-training becoming more popular. E-learning market in developed countries is very complex with many market segments but the three segments are main and they capture the general trends of e-learning (Georgakellos, Macris, 2009, 231-240).

Content providers create and publish educational and learning material and software as intellectual property. Technology vendors provide tools and learning-specific hardware, enabling the creation, delivery, and management of virtual learning environment. Service providers offer learning-related services, which can be categorized in three groups: portals, learning service providers, and other professional services.

E-learning and IT-based training makes many opportunities for education institutions, business organizations and trainees. These opportunities are: effective use of information and communication technologies; delivery of educational services anywhere, anytime and anyone; substantial cost savings; just-in-time access to timely information; personalized learning; improved collaboration and interactivity; convenience of on-line training (Sulčič, Lesjak, 2009, 40-47).

Effective use of information and communication technologies. Information technology has made substantial changes in learning and training. Traditional classroom-based training is too costly and inconvenient for many organizations which need more modern, efficient, and flexible alternative, such as e-learning. Aim of corporate e-learning is to obtain an up-to-date and costeffective program to employees. The effects of the learning are highly motivated, skilled, and loyal knowledge workers.

Delivery of educational services anywhere, anytime and anyone. The Internet is a good technical solution for education, learning and training. Many technical obstacles for a wide use of the Internet (access, standards, infrastructure, and bandwidth) are removed. The growth of the World Wide Web, high-capacity corporate networks, and high-speed desktop computers have improved learning process.

Substantial cost savings. When conducted electronically, the training is less expensive per user due to efficient distribution and the elimination of high salaries for trainers and consultants. The biggest benefit of e-learning is the elimination of the expense and inconvenience of getting the instructor and students in the same place. 
Just-in-time access to timely information. Web-based training services allow instructors to easily and instantly update lessons and learning materials. This keeps educational content fresh and consistent. Learners have immediate access to the most current information that can be retrieved just before it is required.

Personalized learning. Personalized learning impact on higher retention of learning content. There are individual differences in learning styles and elearning supports all the styles. E-learning also provide a high level of simulation suitable to the learner's level of proficiency. People can learn at their own pace and review course material as often as needed. They can customize the learning material to their own needs, control their learning process and better understand the material.

Improved collaboration and interactivity. Electronic learning offers more collaboration and interaction with experts and peers than traditional learning. Teaching methods and information communication technologies which create an interactive on-line environment are: case studies, demonstrations, simulations, streamed videos, on-line references, coaching and mentoring, discussion groups, project teams, chat rooms, e-mail, bulletin boards, tutorials, FAQs, and wizards.

Convenience of on-line training. On-line training is less intimidating than classical courses. Trainees can try new ideas and make mistakes without exposing themselves. It is particularly important when they try to learn soft skills, such as leadership and decision making. A good training program presents the results of students' actions and after a failure, they can go back and try again.

\section{Issues of Training in Crisis Management and Possible Technology Solutions}

In some domains, traditional training approaches have serious limitations. Many of these limitations can be reduced with the use of IT-based training system. Such specific domain that requires technology solution is crisis management so we need to understand the unique challenges in crisis management training and the role of training systems for crisis management based on contemporary information technologies. Blueprint of such system presented in the paper is consists of three components: simulator, multimedia interface and expert system. Simulator generates large numbers of realistic scenarios, an immersive multimedia interface helps elicit psychological processes involved in the actual crisis management, and a critiquing expert system provides real-time feedback on human decisions. Described IT-based training system should has realistic attributes considering the psychological domain of decision making and should improve the decision making. The advantages of training with the system are 
great compared to conventional training or no computerized systems (Sniezek et al. 2002, 147-168).

Effective management during crises is crucial, but it is difficult to train managers appropriately. Crises are very risky situations and it is not suitable situations for training on crisis management. The first aim in crisis management is to quickly gain control of the situation and to minimize loss Crises are rare situations and when they occur priority is not to train novices for crisis management or conduct research in this domain. The contemporary method of training based on information technology has not such limitations and disadvantages. As we mentioned, the training system based on contemporary IT consists of an immersive interface, crisis simulation, and critiquing system. The training system enables trainees to receive immersive practice and experience so trainees can create the skills necessary for crisis management. By using this system trainee is in a situation of the real decision making process where it is possible to get real experience related to the overload and anxiety associated with real crises. The system has unique capabilities which are very significant for resolving many characteristic training issues specific for crisis management.

In order to gather information on many crisis characteristics trainees can use crisis simulations which are component of the training system. This component in the form of sophisticated simulations is very useful in basic research as well as in the transfer of training. Since the research on human performance under acute stress is quite important for the success of crisis management training, researchers can evaluate this performance. The IT-based system for crisis management can be used for research on the basic psychological process of decision-making. Also, it can be used for research in additional areas such as natural language and time perception. Such research can support managers to improve the human performance in crisis management and develop advanced training systems.

Before detailing the presentation of model of IT-based training system for crisis management, we will see which basic issues and challenges in training in crisis management exist.

\subsection{Issues and Challenges in Training in Crisis Management}

Crises in the economic field have many forms, such as a hostile takeover of a company, stock market crash, political change with huge economic implications etc. Also there are crises in many other areas such as a devastating earthquake, airplane crash, food or fuel shortage, etc. Regardless of the domain, crises usually have four features: uncertainty, rapid emergence, possibility of losses, and a lack of control (Sniezek et al. 2002, 147-168). 
A particular problem for managers attempting to resolve the crisis situation is the uncertainty of the crisis events. Usually the managers have not information on the cause of the event making crises and its extent or duration. In addition, there is not defined procedure for managing the crisis and how to proceed to manage the crisis. In order to make the right decisions, the managers need to know the possible course of events and how to allocate resources for managing the events. The uncertainty is caused by the rapid emergence of the crisis, complexity and unpredictability of the events which constitute the crisis.

Rapid emergence of events that require fast action is the first sign that the crisis exists, although sometimes some long term processes lead to a crisis. The main aim of crisis management is to respond to a crisis situation in order to prevent or decrease the negative consequences of the crisis. We should emphasize that only events which cause value loss is marked as crises. Preventing value loss is a very difficult task, though there is the urgency to take effective action. In addition, the value loss in crisis situations is usually irreversible. Managers are able to partially impact on the events of the crisis, but the events actually cannot be fully controlled. In that sense, crisis management is the set of activities undertaken to make control over the events of a crisis to eliminate or reduce losses.

Crisis management is similar to risk management, but there are great differences. For example, in crisis management the events are real, but in risk management, the events are not real but possible. Also in crisis management, activity precedes planning, but in risk management planning precede actions. In crisis management, managers have to make right decisions under time pressure and uncertainty and this is vital for decision-making effectiveness. However, the decision-making process is very complicated because many factors impact on crises. For example, time pressure impacts negatively on the quality of human judgment and training is one solution for increasing the experience level of managers in crisis management.

It is difficult to acquire the skills and knowledge for crisis management because the skills are a very complex. Factors that influence on this can be described as follows:

1. Experience in decision-making during crisis situations is difficult to acquire because the situations are rare. It is very difficult to examine cause-effect relations in crisis situations because extremely uncertain and complex environment of a crisis is not appropriate for this examination. On the other side, acquired experience is not always useful.

2. Conditions in time of crisis are not suitable for training. Managers with some level of expertise and experience for crisis management have no time to train and teach novices because they must act very quickly in a crisis 
situation. In addition, it is not so smart for novices to passively observe behavior of experts in crisis situation.

3. Acquired skills and experience in managing some crisis situation is unique in this situation and is not applicable for the next crisis situation. In other words, the skills and knowledge of crisis management are not general enough to be applicable in every situation. Complexity and uncertainty of crisis situations are very high so that each crisis has unique characteristics. In addition, the skills and knowledge required for effective crisis management have to be upgraded continuously. Reason for this is the environment of crisis that is dynamic and that causes continually change in the procedures and technology for managing crises.

4. We have already mentioned that crisis situations are very rare. This fact causes problem in learning about crisis management because a trainee has a rare opportunity to experience. In addition, when crisis happens, the manager usually is not able to learn and examine it. Finally, even manager has the opportunity and ability to learn, it is possible to learn some wrong things, or things that are not applicable in the next crisis.

Training programs are usually used in learning and acquiring knowledge and skills on crisis management. There are many forms of the programs, and many theoretical and practical issues related to developing a training program for crisis management should be analysed. This analysis has technological, human resource managerial and psychological perspectives (Whitaker et al. 2010, 11-42).

Identification and analysis of trainees' requirements are a main issue in creating a crisis management training program. Domain experts can support the creation of the programs, but recruitment and selection of the experts are a special problem. Managers with experience with past crises can give useful information, but there is the limited number of such experts with current and applicable expertise. Beside this, direct experience with crises of any expert is limited. On the other hand, experts may have different attitude about training content so participation of several experts in the creation of the content can cause disagreement among them. Also, these experts often cannot forecast the exact nature of a future crisis.

The mentioned problems in development of training programs can decrease reliance in the programs. Trainees have an attitude that the programs cannot obtain the necessary knowledge and skills. Regardless of the problems in developing the content of the training programs, domain knowledge, procedural knowledge as well as general strategies for problem-solving are vital for crisis management. In order to be effective in solving problems, managers require a wide range of skills such as communication, social, perceptual, and decisionmaking. All these skills wide the scope of training and this complicates the training process (Chatterjee, 2013, 7-19). 
Groups or teams of employees working on common tasks or projects exist in almost every organization. Interactions between members of teams are essential in crisis management, but there is the problem in the organization and implementation of team training. The best solution is to organize a training program for all members of the team. However, it is difficult to implement when each member needs individualized, specialized training for specific responsibilities. Also, some members of team have important responsibilities outside the team so it is not suitable to train the team as whole.

Beside definition of the training program content, there is the problem of evaluating the success of trainee in adopting knowledge and skills. There are two of trainee assessment. The first goal of measuring success is to make personnel decisions such as whether the trainee has successfully completed the training or not, whether the trainee requires additional training or not, etc. Second goal is to collect data on trainees' performance for analysing the value of a training program. Therefore, measuring the success of the training process is a useful activity in the evaluation of individual performance or the training program as a whole. However, the measures of performance are difficult to create and implement (Kelly, Nanjiani, 2005, p. 124).

Information about success in training is also useful as feedback that can be used to improve performance and increase success of trainees in acquiring appropriate skills and knowledge. The feedback should be prompt and specific if we want to be effective. Feedback on outcomes or errors is not enough, but there is need for explanation that can support the trainee to better understand events in the crisis. The trainee should be able to derive information from the explanation about actions which need to be taken or not taken. Useful and practical instructions are better than generic information on overall rules. Useful instructions are directed at the specific skills which the trainee lacks. By these instructions trainees can improve their understanding and to verify or supplement their own explanations as well. In the case of technology-based system supporting training program, trainees can reconcile contradictions between their expectations and the system recommendations.

Interaction between the trainer and trainee is crucial for the creation and communication of feedback about success of individual trainee in acquiring knowledge. The feedback is created and communicated after execution of actions in a crisis scenario and can be unidirectional or bidirectional. Unidirectional communication taking place from the trainer to the trainee is the simplest form of interaction between people. On the other side, two-way communication is more expensive than interactions of a single trainer with multiple trainees (Robert, 2005, p. 68).

The only real training program can support trainee in acquiring the appropriate knowledge and skills for real crisis situations. Classic forms of 
training such as classroom training and reading educational materials are least expensive but they are not realistic. The most realistic training programs obtain contexts that is the most similar to the context of an actual crisis. Active training is more effective than passive training and only realistic training can obtain a context for active participation of trainees in the process of acquiring skills. On the other hand, classroom training has many disadvantages such as a lack of realism in training programs that can prevent acquiring the most significant skills required in the real environment of crisis (for example, ability to undertake some activities under time pressure). Combination of natural and simulated features is usually required for realistic training. However, financial and ethical factors prevent the real scenario of crisis where the environment simulates real events that lead to real losses. Appropriate training contexts should simulate crisis events on most approximate manner, but even very expensive simulations that represent crisis events are not realistic enough.

Training program should be realistic and simulate the same psychological processes that exist in an actual crisis. The processes are associated with the acute stress emerging in real crises and simulation the processes is the greatest problem in training in crisis management. Acute stress is a psychological state caused by potential harm, time pressure, and arousal, which represent features of crisis management. Decreasing in human performance under stress usually occurs so that the purpose of the training program for crisis management is preventing it. Possibility for research on human performance under acute stress is limited because it is difficult to develop a realistic context of crisis due to ethical and financial reasons. The reasons are already mentioned in the previous consideration of issues for training in crisis management. However, cognitive damage during acute stress is higher for some personality types of people than for others (Levy et al. 2013, 75-84).

The human performance mainly depends on the manner in which an individual evaluates the level of potential harm and time pressure. Simulation and learning from these simulated processes during training program can change the evaluation process. A training program should obtain the trainee with the knowledge and confidence. The knowledge creates the positive expectations and causes effective task performance under stress. Training of people to achieve tasks under acute stress, or some combination of arousal, time pressure, and anxiety are an effective way for improvement of crisis management under acute stress.

Transfer of knowledge and skills from the trainer to trainees is an issue that should be solved in almost any training program. Realistic training program is directed to improvement of trainees' ability for application of acquired skills in the environment of an actual crisis. Two additional factors preventing transfer of knowledge for crisis management are related to the dynamic nature of crises. First, physical, social, or economic factors can change the nature of crises over 
time. Second, crisis management technologies and procedures can change. The dynamic nature of crises means that knowledge and skills acquired for one crisis may not be suitable to another crisis. Providing an appropriate number of novel crisis scenarios is a tremendous task in the development of a training program for crisis management. The scenarios support trainees in preparation for future crises.

\subsection{Model of IT-Based Training System for Crisis Management}

An alternative to traditional training programs for crisis management is advanced programs based on information technology (IT). Also, the advanced programs can be used as a supplement to traditional training programs. Computer-based systems for training that improve learning process can be in many forms. However, computer-based training system for crisis management encompasses three components: an immersive multimedia interface, a crisis simulator, and a critiquing system. The components presented in Figure 1, have the following features: a simulator generates training examples, an immersive interface replicates the information overload that exists in many crisis situations, and a critiquing system creates the feedback that trainer usually gives. (Sniezek et al. 2002, 147-168)

The critical issues in training in crisis management can be solved by ITbased training system. The expert critiquing system is designed to solve the problem of a shortage of experts in training, but human experts are needed in providing the necessary knowledge for designing the critiquing system and crisis simulator. The experts also have a crucial role in testing and validating the training system. However, when the system is finished, the real advantage of the expert critiquing and simulation system is realized. Several versions of the ITbased trainer allow simultaneous training of many trainees. Training from multiple experts in a complex domain usually lacks standardization, but replication of the developed system provides standardization in training.

Technological solution in form of IT-based training system for crisis management changes focus of training programs. Traditional training programs are focused on trainer and emphasize teaching, but training with IT-based training system is focused on trainee and emphasizes learning. However, in traditional training programs as well as in IT-based training experts in specific domain obtain necessary procedural knowledge which represents the context of training. Knowledge is derived from multiple experts in the process of development of an IT-based system so this knowledge is more comprehensive than knowledge elicited from any individual expert. This solution enables developers to build a system that can simulate a great number of crisis scenarios. The scenarios allow trainees to acquire a wide range of skills such as recognizing patterns, detecting signals, coordinating with team members, 
communicating effectively, predicting outcomes of events, making decisions, and remembering protocol. The scope of training in crisis management is expanded due to the comprehensive knowledge base and ability to simulate many scenarios (Pahl, 2006, 101-121).

Figure 1 Components of computer-based training system

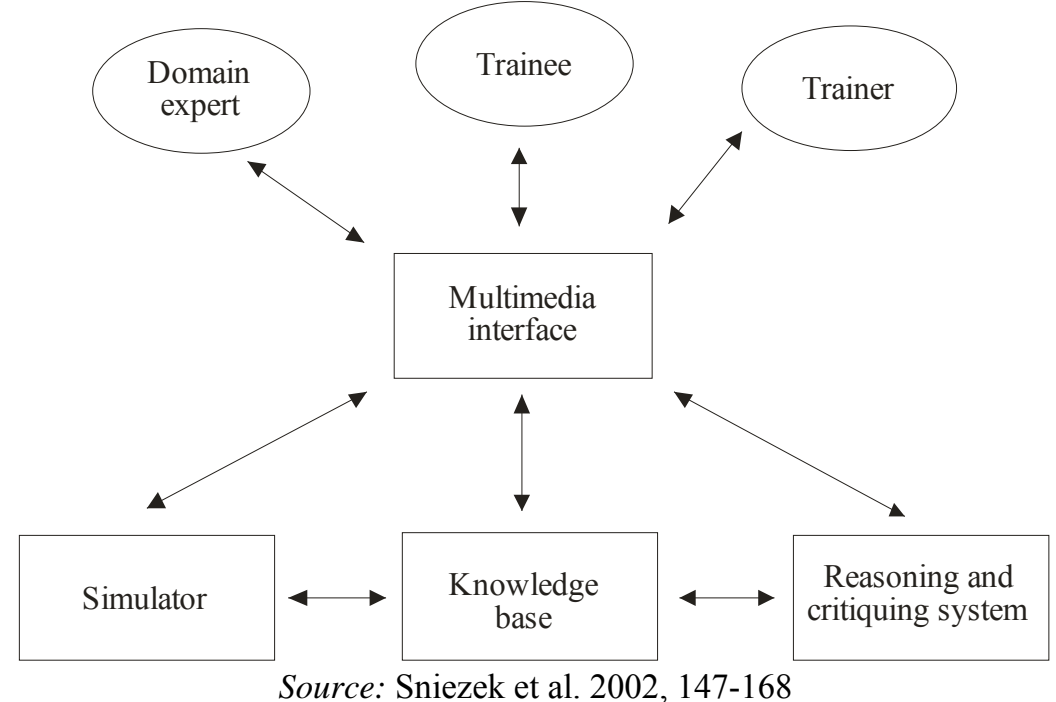

A simulator can be used in simulation of many aspects of crisis management process. The traditional training system does not enable it where the trainer has to interact with all members of a team. Conducting training of the team is improved due to simulation of team behaviors. In this simulation, intelligent agents play roles of people and this advanced training program allows a great number of human behaviors in many crisis scenarios. An expert critiquing system is useful in analysis of simulated crisis scenarios and taking the actions to control it. The system can also be used for evaluation of the trainee's success in acquiring knowledge according to predetermined criteria.

Expert reasoning system obtains more effective a trainee's performance analysis than traditional training system. Subjective methods of performance evaluation where the trainers assess trainee's success in acquiring knowledge and skills are used in traditional training. These methods are focused on outcomes which are easily observed, but advanced technology-based methods are directed to process of reasoning and decision-making during crisis. Outcomes are not suitable parameter of performance in crisis decision making, because losses are almost inevitable in crisis and the losses are not always a result of poor crisis management. Performance evaluation with an expert critiquing system is focused on the quality of the reasoning process used in managing the crisis. 
Providing performance feedback to the trainee is a key feature of any intelligent tutoring system so it is the real benefit of a. Besides that the system enables the development of optimal decision strategies, the system should obtain effective learning of trainees from it. In any training program, it is significant that trainees understand their shortcomings in the training process. In conventional training program, trainer suites feedback to individual requirement of trainees. It is a very labor-intensive task because the trainer must analyse and understand the reasoning of the trainee, the events that constitute the crisis and the activities taken by the trainee as a response to the events. An expert critiquing system can do this analysis automatically, in real time, with fast feedback. The main focus of the feedback is the trainee's process of learning, rather than the outcomes only. Feedback considering process of decisionmaking is more important than feedback related to the outcome of the process of human decision-making. In this process sometime feedback does not suite the intuition and opinion of trainees so it is possible that they reject the feedback and miss to improve success in learning process and performance. Explanations of results are crucial for trainees to understand and accept feedback so it is important to include these explanations in the system. The explanations also increase trust, which in turn improves the acceptance of feedback.(Sniezek, van Swol, 2001, 288-307), (Ye, Johnson, 1995, 157-172).

Different levels of expertise and levels in a hierarchy of goals require different types of feedback. Thus the feedback has to be adapted to these levels. The feedback that focuses on lower levels of the hierarchy is best for initial learning on complex tasks. However, as the trainees' skill improves, feedback is directed to general task performance. An expert system can provide feedback about performance at any level and at the right time and the explanation of the decision-making process and outcomes is adapted to the experience level of the user. Therefore, trainees with more experience in certain domain of decisionmaking require different explanations than those with less experience.

IT-based training system can support the improvement of communication of feedback and other performance information. If we take into account nature of interactions with the trainee, an expert critiquing system is very flexible supporting many types of interaction. The system can analyze events and actions as they occur obtaining information to the trainee in real time. Beside this, communication is bidirectional and individualized so this can enhance trainee performance. The bidirectional interactions and ability to initiate interaction at any time obtain large advantages. This communication environment enables the expert to deliver advice or feedback at any time and the novice can request such assistance also at any time. In this environment, the trainee receives advice and then take actions based on it. It is better for trainee than taking faulty actions and subsequently trying to correct them. Trainers use different methods and techniques in communication with trainees and some of them do not consistently 
use the most appropriate teaching techniques. However, an expert system provides most suitable teaching methods such as asking questions, giving recommendations and suggestions and eliciting self-explanation.

Effective expert critiquing and simulation system provides conditions for training that can occur at any place and any time. By this system, problem of selection of the time and place of training and choice of appropriate materials needed for crisis management training is resolved. Computer with moderately high performance is required for supporting the training and this makes the computer-based training system more flexible so an employee could train at home. This feature of flexibility means removal of obstacles to practice and increasing actual training time. Opportunity for practice is necessary for effective training. In order to realize the benefits of critiquing, trainee must understand shortages in skill and then practice the skill in a specific context.

The greatest problem in a training in crisis management based on IT is a cost of development of a system that supports the training. The initial research and development costs of an IT-based training system with advanced simulation functions is very high. Prediction of the initial costs of system development is a difficult task. However, prediction of implementation and maintenance cost is possible with reasonable accuracy. Cost of development of the system supporting the training will decrease in the future due to reduction of hardware and software costs. Also, the cost of expert training systems development will be decreased with the further advancement of technology.

Improvement of knowledge transfer is the very great benefit of a simulator presenting scenarios to trainees. Main advantage of technology-based training is an active learning environment which the simulator creates. A simulator with this feature is particularly significant in training in crisis management. The reasons for that are the following:

1. The simulator makes training more realistic because it evokes the psychological processes which exists in crisis management. Main psychological processes in crisis management are influenced by acute stress so simulations create a state of acute stress for trainees. Following components support creation of acute stress: multimedia interfaces with graphic representation of losses resulting from a crisis, time pressure, information overload etc. Requirement for information processing is very high in a crisis and representation of crisis conditions increases the information load.

2. The creation of a great number of novel scenarios is an important function of the simulator. The main purpose of the simulator is to expose trainees to a large number of scenarios and large number of different types of scenarios. Training with many different scenarios increases ability of the trainee to overcome uncertainty and enhances transfer of knowledge. Experience in 
managing many crisis scenarios increases the ability of trainee to manage novel crises.

\section{Conclusion}

Many unique problems in crisis management training require a complex skill. In this paper, we analyze the issues existing in developing a crisis management training program and the benefits of IT-based system supporting crisis management training. The model of the system presented in the paper is consisted of an immersive interface, expert critiquing, and scenario simulator. This system can be useful in evaluating and comparing various programs for crisis management training. Several novel scenarios that the system can create is very useful for in crisis management training. An expert critiquing component of the system provides automated evaluation of human performance. This can be a useful model for training programs in general.

A computer tutoring system is necessary but not sufficient for any crisis management training program. A complete IT-based system that supports a training program for the crisis management requires the integration of three components: an immersive interface that creates a psychologically realistic experience; a simulator with many scenarios of varying attributes and difficulties; and a critiquing system that can obtain real-time feedback and maintain flexible communication between the system and trainee. The paper provides the foundation for further research in the development of IT-based training programs appropriate to specific domains. Creation of any training system needs serious consideration of the training issues discussed in this paper. A successful IT-based training system provides reduction of the gap between training needs in crisis management and the system capabilities. Specific problems of a particular domain may require new variations on a training solution. The framework presented in the paper can be a useful for examination of these problems, and formulation of solutions.

\section{References}

Al-Busaidi, K.A. (2012) "Learners' Perspective on Critical Factors to LMS Success in Blended Learning: An Empirical Investigation", Communications of the Association for Information Systems, 30: 11-34.

Azevedo, H. J., Scalabrin, E. E., (2005) „A Human Collaborative Online Learning Environment Using Intelligent Agents“, in Fuhua Oscar Lin (ed.), Designing Distributed Learning Environments with Intelligent Software Agents. Hershey: Information Science Publishing, pp. 5-24.

Chatterjee, S. (2013) "Constraints in Organizational Learning, Cognitive Load and Its Effect on Employee Behavior", IUP Journal of Knowledge Management, 11(4): 7-19.

Driscoll, M., Carliner, S. (2005) Advanced Web-based Training Strategies - Unlocking Instructionally Sound Online Learning, San Francisco: John Wiley\&Sons. 
Franceschi, K., Lee, R.M., Zanakis, S.H., Hinds, D. (2009) "Engaging Group E-Learning in Virtual Worlds", Journal of Management Information Systems, 26(1): 73-100.

Garcia, R., Pariente, T. (2009) "Interoperability of Learning Objects Copyright in the LUISA Semantic Learning Management System", Information Systems Management, 26(3): 252-261.

Georgakellos, D.A., Macris, A.M. (2009) "Application of the Semantic Learning Approach in the Feasibility Studies Preparation Training Process", Information Systems Management, 26(3): 231-240.

Gupta, S., Bostrom, R.P. (2009) "Technology-Mediated Learning: A Comprehensive Theoretical Model", Journal of the Association for Information Systems, 10(9): 686-714.

Jingyuan, Z., Ordonez de Pablos, P. (2009) "School Innovative Management Model and Strategies: The Perspective of Organizational Learning", Information Systems Management, 26(3): 241-251.

Kelly, T., Nanjiani, N. (2005) The Business Case for E-Learning, Indianapolis: Cisco Press.

Koohang, A., Paliszkiewicz, J. (2013) "Knowledge Construction in E-Learning: an Empirical Validation of an Active Learning Model", Journal of Computer Information Systems, 53(3): 109-114.

Kuang-Yuan, H., Güney, S. (2012) "Toward a Framework of Web 2.0-Driven Organizational Learning", Communications of the Association for Information Systems, 31: 128-152.

Levy, Y., Ramim, M.M., Hackney, R.A. (2013) "Assessing Ethical Severity of ELearning Systems Security Attacks", Journal of Computer Information Systems, 53(3): 75-84.

Milovanovic, S. (2010) „Opportunities and Challenges of Electronic Learning“, Facta Universitatis, Series: Economics and Organization, 7(2): 191-199.

Morrison, R., Cegielski, C.G., Rainer, R. K. (2012) "Trust, Avatars, and Electronic Communications: Implications for E-Learning", Journal of Computer Information Systems, 53(1): 80-89.

Pahl, C. (2006) „A Conceptual Architecture for Development Interactive Educational Multimedia“, in Zongmin Ma, (ed.), Web-based Intelligent E-learning Systems Technologies and Applications, Hershey: Information Science Publishing, pp. 101121.

Robert, T. S. (2005) Computer-supported Collaborative Learning in Higher Education, Hershey: Idea Group Publishing.

Santhanam, R., Sasidharan, S., Webster, J. (2008) "Using Self-Regulatory Learning to Enhance E-Learning-Based Information Technology Training", Information Systems Research, 19(1): 26-47.

Shi, Z., Whinston, A.B. (2013) "Network Structure and Observational Learning: Evidence from a Location-Based Social Network", Journal of Management Information Systems, 30(2): 185-212.

Sims, J., Vidgen, R., Powell, P. (2008) "E-Learning and the Digital Divide: Perpetuating Cultural and Socio-Economic Elitism in Higher Education", Communications of AIS, 2008(22): 429-442. 
Sniezek, J. A., Wilkins, D. C., Wadlington, P. L. and Baumann, M. R. (2002) „Training for Crisis Decision-Making: Psychological Issues and Computer-Based Solutions“, Journal of Management Information Systems (18)4: 147-168

Sniezek, J.A., van Swol, L. (2001) „Trust, confidence, and expertise in Judge Advisor Systems“, Organizational Behavior and Human Decision Processes, (84)2: 288-307.

Sulčič, V., Lesjak, D. (2009) "E-Learning and Study Effectiveness", Journal of Computer Information Systems, 49(3): 40-47.

Tatnall, A., Osorio, J., Visscher, A., (2005) Information Technology and Educational Management in the Knowledge Society, Boston: Springer Science + Business Media, Inc.

Urdan, T. A., Weggen, C. C. (2000) Corporate E-learning: Exploring a New Frontier, Wr Hambrecht + Co., Equity Research.

Wei-Han Tan, G., Keng-Boon, O., Jia-Jia, S., Phusavat, K. (2012) "Determinants of Mobile Learning Adoption: An Empirical Analysis", Journal of Computer Information Systems, 52(3): 82-91.

Whitaker, J., Mithas, S., Krishnan, M.S. (2010) "Organizational Learning and Capabilities for Onshore and Offshore Business Process Outsourcing", Journal of Management Information Systems, 27(3): 11-42.

Ye, L.R., Johnson, P.E. (1995) The Impact of Explanation Facilities on User Acceptance of Expert Systems Advice, MIS Quarterly (19)2: 157-172.

\section{SISTEM OBUKE ZA UPRAVLJANJE KRIZOM BAZIRAN NA SAVREMENIM INFORMACIONIM TEHNOLOGIJAMA}

Apstrakt: U tranzicionom periodu koji traje više od dvadeset godina u Srbiji, mnoge organizacije funkcionišu $u$ turbulentnom i neizvesnom političkom, ekonomskom i socijalnom okruženju. Velike promene u tom okruženju sa implikacijama koje je teško predvideti postavljaju pred menadžment tih organizacija mnoge krizne situacije. Svaki menadžer koji poseduje standardne veštine i znanje za upravljanje preduzećem mora da stekne dodatne veštine za upravljanje tim kriznim situacijama. Upravljanje krizom je skup akcija preduzetih u kontroli događaja koji čine krizu, da bi se minimizirali gubici. Da bi preduzeo odgovarajuće akcije u vreme krize, menadžer treba da zna pravac kretanja budućih događaja i kako alocirati resurse za reakciju na te događaje. U toj situaciji, veliki problem je neizvesnost koja rezultira iz brze i iznenadne pojave kriznih događaja, njihove kompleksnosti i nepredvidivosti. Sistem obuke koji ima za cilj da osposobi rukovodioce za reakciju na krizne situacije je analiziran u ovom radu. Ovaj sistem je zasnovan na korišćenju savremenih informacionih tehnologija. Osim toga, objašnjeni su trendovi i mogućnosti elektronskog učenja i obuke, kao i izazovi u razvoju programa obuke za upravljanje krizom.

Ključne reči: Upravljanje krizom, elektronsko učenje, sistem obuke, informacione tehnologije 